\title{
The balanced lethal system of crested newts
}

\author{
H. WALLACE \\ School of Biological Sciences, University of Birmingham, Edgbaston, Birmingham B15 2TT, U.K.
}

\begin{abstract}
Matings of Triturus cristatus carnifex consistently produce two embryonic lethal phenotypes (fattailed and slim-tailed) and viable larvae in the 1:1:2 proportions expected for a balanced lethal system. A marker variant of chromosome 1 is used to show fat-tailed embryos are $1 \mathrm{~A} / 1 \mathrm{~A}$ homozygotes, slim-tailed embryos are $1 \mathrm{~B} / 1 \mathrm{~B}$ homozygotes and viable ones are $1 \mathrm{~A} / 1 \mathrm{~B}$ heterozygotes. Another embryonic trait (dorsal blisters), which is expressed in the lethal phenotypes of some matings, is found to be incompletely linked to the recessive lethal factors.
\end{abstract}

Keywords: balanced lethal, cytogenetics, C-banding, Triturus, Urodeles.

\section{Introduction}

Newts of the Triturus cristatus species group, including the subspecies or species referred to here as cristatus and carnifex, and the closely related $T$. marmoratus exhibit a balanced lethal system associated with heteromorphism of chromosome 1 . The heteromorphism is most obvious in oocyte lampbrush bivalents where the long arm of chromosome $1 \mathrm{~A}$ is usually longer than that of $1 \mathrm{~B}$ and has a different distribution of prominent loops (Callan \& Lloyd, 1960; Mancino, 1991). Less obvious differences between the corresponding heterochromatic segments of $1 \mathrm{~A}$ and $1 \mathrm{~B}$ have been detected by C-banding spermatocyte bivalents (Mancino et al., 1977; Morgan, 1978) and somatic chromosomes (Macgregor \& Horner, 1980; Sims et al., 1984). All adult animals examined are heterozygous for this chromosome and only about 50 per cent of the embryos from any spawning hatch as viable $1 \mathrm{~A} / 1 \mathrm{~B}$ larvae. The remaining embryos which are arrested at tailbud stages should comprise the two homozygous classes, 25 per cent $1 \mathrm{~A} / 1 \mathrm{~A}$ and 25 per cent $1 \mathrm{~B} / 1 \mathrm{~B}$. Examples of each class have been identified by the rather variable $\mathrm{C}$-banding patterns but no other phenotypic difference between homozygotes was noticed in the initial reports, preventing any estimate of their frequencies (Macgregor \& Horner, 1980; Sims et al., 1984; Wallace, 1984).

A reliable phenotypic difference between arrested embryos has since been discovered, as they have either a short fat tailbud (FT) or a longer slim tailbud (ST). Examples were illustrated without comment by Horner \& Macgregor (1985) and described in detail by Sessions et al. (1988). The latter report found that FT embryos were $1 \mathrm{~B} / 1 \mathrm{~B}$ and $\mathrm{ST}$ embryos were $1 \mathrm{~A} / 1 \mathrm{~A}$ homozygotes and counted almost equal numbers of FT and ST phenotypes in one sample of arrested embryos collected from a natural population of cristatus. The FT phenotype was incorrectly described as part of a syndrome involving a persistent yolk plug in this report but it is equally evident after perfect gastrulation in normal culture conditions which yield the expected Mendelian ratios of FT, ST and viable embryos in cristatus (Wallace, 1991).

Another phenotypic difference between arrested embryos has been described in carnifex. Embryos from some spawnings of a laboratory stock developed dorsal blisters over the brain and spinal cord at the head process stage (shortly after closure of the neural folds). Such embryos were almost always arrested at tailbud stages, constituted about 25 per cent of the tailbud embryos and were tentatively associated with homozygosity for a relatively distinct variant of chromosome 1A (Wallace, 1987). The present article describes how descendents from this stock have been used to investigate three aspects of the balanced lethal system in carnifex: if FT, ST and viable phenotypes consistently occur in Mendelian proportions; whether the dorsal blister trait is associated with the FT or ST phenotype; and which variant of chromosome 1 occurs in which arrested phenotype.

\section{Materials and methods}

The main (M) carnifex stock has been maintained in the laboratory for over 10 years. It is sufficiently inbred to reveal several recessive larval lethals, although matings between identified individuals only extend to the last three generations. A second $(\mathrm{S})$ stock is descended from three adults imported from Pavia in 1991.

Female newts are capable of multiple mating and can store sperm for several months. To ensure known paternity, each female was isolated before and after mating and not remated in the same year unless it laid 
unfertilized eggs. Male newts show nuptial characters and mate spontaneously for unpredictable periods between January and June, provided the aquarium temperature remains below $15^{\circ} \mathrm{C}$. A male in breeding condition was introduced to the chosen female in a mating tank at $18^{\circ} \mathrm{C}$ for no more than a week. The male usually began the courtship display within a day and was removed as soon as the female began to lay fertilized eggs. The male often was mated with another female directly afterwards. The bulk of the results were thus obtained from 12 matings involving 13 specimens: four $M$ stock males each mated to a different $S$ stock female and to one or more $M$ stock females, three of which were mated to different males in consecutive years.

Eggs were collected daily from nylon ribbons suspended in the mating tank and cultured in water as batches of up to 20 in plastic Petri dishes at $20^{\circ} \mathrm{C}$. Embryos with dorsal blisters were isolated from some spawnings and recorded from large samples for all the others, before scoring the tailbud phenotypes. Small samples were taken for chromosome preparations and C-banding as described previously (Wallace, 1987). C-banding identifies the mainly heterochromatic long arm of chromosome 1 and reveals a polymorphism within the $M$ stock. A dark-ended form of chromosome 1 , called $1 \mathrm{Ad}$, is readily distinguished from the standard pale-ended $1 \mathrm{Ap}$ and from $1 \mathrm{~B}$, even when it is impossible to discriminate between $1 \mathrm{Ap}$ and $1 \mathrm{~B}$.

\section{Results}

The $M$ stock has been selected over two generations from spawnings which included embryos with dorsal blisters. All the present stock carry the marker chromosome $1 \mathrm{Ad}$, except for one male which carries the standard chromosome $1 \mathrm{Ap}$. The $\mathrm{S}$ stock are all $1 \mathrm{Ap} / 1 \mathrm{~B}$ and no blistered embryos occurred among the progeny of two matings from the imported specimens.

The general characteristics of 12 matings obtained during the last 2 years are summarized in Table 1. Mated females usually laid batches of 20-60 eggs on successive nights for up to 5 weeks, producing 200-900 eggs according to age and size. Fertility often exceeded 90 per cent in the mid-spawning period but uncleaved eggs or abortive cleavage were more common in early and late spawning periods. There was a gradual attrition of developing embryos by explosive expulsion through the capsule, perhaps indicating damage during collection. These are the principal causes for the reduction of the number of collected eggs to 86 per cent by the head process stage. Less than 1 per cent of blastulae showed abnormal gastrulation or neurulation and less than 2 per cent of the neurulae failed to reach a scorable tailbud stage.
Dorsal blisters were first observed when neurulae began to elongate as head process or early tailbud stages. The incidence of blistered embryos ranged from 0 to 26 per cent in large samples from these matings and is considered in more detail later. The blisters accurately predicted later arrest, usually as embryos with relatively small tailbuds which could still be classified unambiguously as FT or ST phenotypes (Fig. 1). Tailbud embryos are recorded in Table 1 as arrested FT and ST and as normal embryos which later hatched as viable larvae. The proportions of these categories are extremely close to the predicted Mendelian ratios $\left(\chi_{2}^{2}=0.0007 ; P>0.95\right)$ and occurred consistently in all 12 matings (heterogeneity $\chi_{22}^{2}=16.8157 ; P>0.7$ ).

\section{Dorsal blisters}

The presence of dorsal blisters at the head process stage is the only known means of identifying a subset of homozygotes prior to their developmental arrest. It is a variable trait, however, and has only been recorded from some spawnings of this laboratory $M$ stock. The blisters contain cell debris from the necrotic central nervous system and usually persist until well after development has ceased (Wallace, 1987). Some blisters burst, releasing debris into the capsular fluid; others merely subside after a day and may occasionally reappear later.

Only five of the spawnings listed in Table 1 produced embryos with large or multiple, persistent dorsal blisters. These embyros were isolated so that their subsequent fate could be recorded (Table 2). An analysis of the data shown in Table 2 supports the interpretation that dorsal blisters are caused by a dominant allele which is only expressed in arrested embryos and which is incompletely linked to the tailbud phenotype. The totals fit a 3:1 segregation of smooth and blistered embryos $\left(\chi_{1}^{2}=0.0002 ; P>0.95\right)$ and the expected $1: 2: 1$ ratio of tailbud phenotypes $\left(\chi_{2}^{2}=0.3788\right.$; $P>0.8)$ and all five samples are homogeneous in these respects. About 90 per cent ST developed from blistered embryos and 90 per cent FT from smooth ones. Consequently, the minor categories of arrested embryos (blistered FT and smooth ST) appear to be recombinants. The pooled recombination frequencies among arrested embryos in Table 2 ( 11 per cent for $\mathrm{M} \times \mathrm{M}$ matings and 6 per cent for $\mathrm{S} \times \mathrm{M}$ matings) are significantly different $\left(\chi_{1}^{2}=5.6828 ; P<0.05\right)$. This might reflect the opportunity for recombination in either parent of the former cross in contrast to exclusively paternal recombination in the latter cross.

Another six matings listed in Table 1 produced embryos with a single small dorsal blister which rarely persisted for more than 1-2 days. Such embryos were identified at lower frequencies of 13-21 per cent, 
Table 1 Summary of spawning data from 12 matings

\begin{tabular}{|c|c|c|c|c|c|c|}
\hline \multirow{3}{*}{$\frac{\text { Mating } t}{\text { M1 × T15 }}$} & \multirow{3}{*}{$\begin{array}{r}\text { Eggs } \\
841\end{array}$} & \multirow{2}{*}{\multicolumn{2}{|c|}{$\begin{array}{l}\text { Head process } \\
\text { (\% blistered) }\end{array}$}} & \multicolumn{3}{|c|}{ Tailbud } \\
\hline & & & & \multirow{2}{*}{$\begin{array}{l}\text { FT } \\
181\end{array}$} & \multirow{2}{*}{$\begin{array}{l}\text { ST } \\
194\end{array}$} & \multirow{2}{*}{$\begin{array}{c}\text { Normal } \\
338\end{array}$} \\
\hline & & 734 & (20) & & & \\
\hline $\mathrm{M} 2 \times \mathrm{T} 4$ & 835 & 661 & (19) & 164 & 153 & 322 \\
\hline $\mathrm{O} 22 \times \mathrm{O} 24$ & 728 & 643 & (21) & 167 & 152 & 319 \\
\hline $\mathrm{M} 4 \times \mathrm{T} 15$ & 966 & 840 & (21) & 192 & 214 & 415 \\
\hline $\mathrm{M} 1 \times \mathrm{M} 16$ & 532 & 492 & $(26)$ & 111 & 120 & 255 \\
\hline $\mathrm{M} 2 \times \mathrm{M} 16$ & 710 & 606 & (13) & 156 & 128 & 311 \\
\hline $\mathrm{M} 3 \times \mathrm{M} 16$ & 245 & 169 & (24) & 38 & 42 & 86 \\
\hline $\mathrm{M} 4 \times \mathrm{O} 24$ & 756 & 668 & $(22)$ & 170 & 168 & 325 \\
\hline $\mathrm{S} 1 \times \mathrm{T} 4$ & 203 & 164 & $(0)$ & 41 & 48 & 74 \\
\hline $\mathrm{S} 2 \times \mathrm{T} 15$ & 216 & 190 & (26) & 41 & 49 & 99 \\
\hline $\mathrm{S} 3 \times \mathrm{O} 24$ & 352 & 344 & (24) & 98 & 84 & 162 \\
\hline $\mathrm{S} 4 \times \mathrm{M} 16$ & 409 & 318 & (13) & 71 & 79 & 157 \\
\hline Total & 6793 & 5829 & & 1430 & 1431 & 2863 \\
\hline Tailbud ratio (\%) & & & & 25 & 25 & 50 \\
\hline
\end{tabular}

$\dagger$ Female $\times$ male: $\mathrm{S} 1-\mathrm{S} 4$ are S stock females, all others are M stock.

Fig. 1 Hatched viable larva and the two arrested phenotypes, all aged 10 days. The larva (top) is about $1 \mathrm{~cm}$ long. ST (left) and FT (right) embryos have been decapsulated to display the characteristic forms of the tailbud. The ST embyro has a dorsal blister above the gill primordia (arrow).

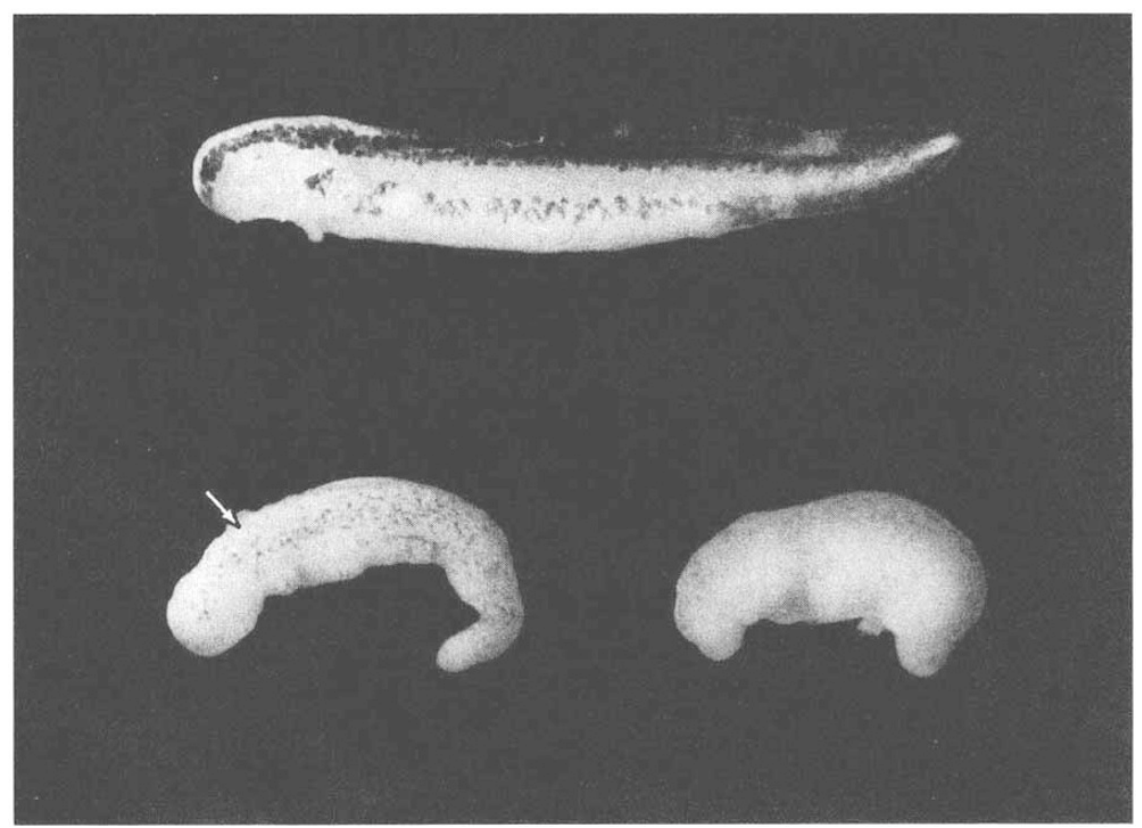

sometimes showing a decline during the spawning period. The majority of blistered embryos developed into the arrested ST phenotype in these cases but the distorted ratios (attributed to inefficient identification) prevented an accurate estimation of recombination values. Finally, one mating between an $\mathrm{S}$ stock female and the only $M$ stock male known to possess $1 \mathrm{Ap} / 1 \mathrm{~B}$ chromosomes yielded no blistered case in 164 head process embryos. This was the result that had been anticipated for all $\mathrm{S} \times \mathrm{M}$ matings, on the assumption that dorsal blisters was a recessive trait, but the other three matings showed the assumption to be invalid. 


\section{Chromosomes}

Metaphase chromosome preparations were obtained from samples of embryos from four of the matings shown in Table 2 and from one earlier M stock mating by culturing blistered ST, smooth FT or normal tailbud stages in colchicine as soon as they could be distinguished. Many of the FT and ST embryos were already virtually arrested and contained few or no dividing cells. Greater numbers of them were cultured to compensate for that and the presumed recombinant phenotypes were excluded. Chromosomes 1Ap and 1B could not be distinguished in most of the preparations so the embryos are classified in Table 3 according to the dark or pale tips of chromosome 1 pairs, which are easily recognized after C-banding (Fig. 2).

The categories recorded in Table 3 are consistent with the known genotypes of their parents, previously scored by larval tailtip preparations. In particular, two classes of normal heterozygotes can only occur in the $\mathrm{S} \times \mathrm{M}$ matings where the parents carry different forms of chromosome $1 \mathrm{~A}$. The associated heteromorphy in FT embryos from the same matings indicates that they must carry both forms of $1 \mathrm{~A}$. The surprising feature of these results is that the blistered ST embyros were all homozygous for chromosome $1 \mathrm{~B}$. That is contrary to my earlier suggestion that $1 \mathrm{~A}$ is associated with dorsal blisters (Wallace, 1987) and to the conclusion reached by Sessions et al. (1988) that cristatus ST embryos are homozygous for chromosome $1 \mathrm{~A}$.

\section{Discussion}

The balanced lethal system considered here was first established by recording approximately 50 per cent embryonic lethality, mainly for cristatus and carnifex but also for other members of the $T$. cristatus group (Macgregor \& Horner, 1980; Horner \& Macgregor, 1985; Wallace, 1984, 1987). Following identification of the FT and ST arrest phenotypes, the expected Mendelian ratios have been demonstrated for cristatus (Wallace, 1991) and for carnifex by the present data. In the interim, there have been repeated arguments for raising the status of the four subspecies of $T$. cristatus

Table 2 Numbers of embryos classified according to head process blisters and tailbud arrest phenotype

\begin{tabular}{|c|c|c|c|c|c|c|c|}
\hline \multirow{2}{*}{$\begin{array}{l}\text { No. and stock } \\
\text { of matings }\end{array}$} & \multicolumn{3}{|c|}{ Without blisters } & \multicolumn{3}{|c|}{ With blisters } & \multirow[b]{2}{*}{ Total } \\
\hline & FT & ST & Normal & FT & ST & Normal & \\
\hline $3 \mathrm{M} \times \mathrm{M}$ & 184 & 22 & 461 & 24 & 199 & 0 & 890 \\
\hline $2 \mathrm{~S} \times \mathrm{M}$ & 131 & 7 & 261 & 8 & 126 & 0 & 533 \\
\hline Total & 315 & 29 & 722 & 32 & 325 & 0 & 1423 \\
\hline
\end{tabular}

to full species (reviewed by Macgregor et al., 1990). They probably hybridize rarely in nature but can produce fertile hybrids in captivity. In contrast, the natural hybrids between cristatus and T. marmoratus are infertile in one sex at least. Retention of subspecific rank thus seems a better reflection of the greater similarity between members of the $T$. cristatus group than any of them have to T. marmoratus. It is certainly more convenient in this context, for $T$. marmoratus exhibits a more extreme heteromorphism of chromosome 1 which is even detectable in the relative length of somatic chromosomes (Sims et al., 1984).

Only minor differences have been noticed between FT and ST phenotypes in either cristatus or carnifex. All embryos develop normally up to the head process stage, when the main organ primordia are present. Cellular differentiation in both phenotypes is limited to a few tissues by the onset of developmental arrest. Cell death is evident in most internal organs and is most abundant in the central nervous system (Wallace, 1987; Sessions et al., 1988). Both FT and ST homozygotes appear to be autonomous cell lethals and may differ mainly in the precise timing of developmental arrest.

The dorsal blister phenotype can be traced back to one or two purchased specimens and thus probably to a single wild population of carnifex. The present results indicate that blisters are restricted to embryos whose development will be arrested. Blisters may be merely symptoms of an increased amount of cell death and accumulated debris in the central nervous system. Contrary to the simplest expectation that the blistered phenotype would be a variant of the balanced lethal system and thus predict either FT or ST, it can be expressed in both FT and ST embryos and appears to be incompletely linked to the arrest syndrome. Although dorsal blisters have been recorded in half the arrested embryos at most, and predominantly in ST embryos (Table 2), recombination implies that neither of these features need apply to a more extensive series of matings.

Cytological considerations impose a constraint on the recombination inferred from the present data. All observations agree that the heteromorphic segment of chromosome 1 is achiasmate in both sexes, hence being inherited as a single unit. Chiasmata have been recorded in the proximal euchromatin of the long arm and either chiasmata or terminal associations occur in the distal euchromatin at a low frequency (Callan \& Lloyd, 1960; Morgan 1978). Accepting that the lethal factors occupy the heterochromatic segment must place the blistering trait in the adjacent euchromatin. The constraint would be more rigorous if one could verify the claim of Sims et al. (1984) that the heteromorphic segment or entire long arm of chromosome 1 apart from its tip is asynaptic in carnifex spermatocytes. 
I cannot dispute that directly but have seen equally convincing cases where bivalent 1 is completely paired at pachytene in carnifex oocytes and in both sexes of cristatus (unpublished data).

The marker chromosome 1Ad was deliberately maintained in the $M$ stock because it could be identified reliably in most $\mathrm{C}$-banded metaphases and because of its presence in spawnings that included blistered embryos. A few blistered embryos were recorded previously as possessing chromosome $1 \mathrm{Ad}$
(Wallace, 1987). However, the five matings shown in Table 3 consistently revealed the absence of $1 \mathrm{Ad}$ from blistered ST embryos. This apparent contradiction may be resolved by assuming that the blistering allele had been exchanged between chromosomes 1 Ad and $1 \mathrm{~B}$ by recombination in the intervening generations of the $\mathrm{M}$ stock. The assumption can be tested quite easily and perhaps extended to determine if the frequency of recombination is compatible with chiasma frequencies in proximal or distal euchromatin.

Table 3 Numbers of arrested (FT and ST) and normal tailbud embryos scored according to dark (D) or pale (P) ends of chromosome 1

\begin{tabular}{|c|c|c|c|c|c|}
\hline \multirow{2}{*}{$\begin{array}{l}\text { No. and stock } \\
\text { of matings } \\
\text { (parent genotype) }\end{array}$} & \multicolumn{2}{|c|}{ Smooth FT } & \multirow{2}{*}{$\frac{\text { Blistered ST }}{\mathrm{P} / \mathrm{P}}$} & \multicolumn{2}{|c|}{ Normal } \\
\hline & $\mathrm{D} / \mathrm{D}$ & $\mathrm{D} / \mathrm{P}$ & & $\mathrm{D} / \mathrm{P}$ & $\mathrm{P} / \mathrm{P}$ \\
\hline $\begin{array}{l}3 \mathrm{M} \times \mathrm{M} \\
(\mathrm{Ad} / \mathrm{B} \times \mathrm{Ad} / \mathrm{B})\end{array}$ & 16 & 0 & 15 & 17 & 0 \\
\hline $\begin{array}{l}2 \mathrm{~S} \times \mathrm{M} \\
(\mathrm{Ap} / \mathrm{B} \times \mathrm{Ad} / \mathrm{B})\end{array}$ & 0 & 13 & 12 & 11 & 13 \\
\hline $\begin{array}{l}\text { Inferred } \\
\text { genotype }\end{array}$ & $\mathrm{Ad} / \mathrm{Ad}$ & $\mathrm{Ad} / \mathrm{Ap}$ & $\mathrm{B} / \mathrm{B}$ & $\mathrm{Ad} / \mathrm{B}$ & $\mathrm{Ap} / \mathrm{B}$ \\
\hline
\end{tabular}
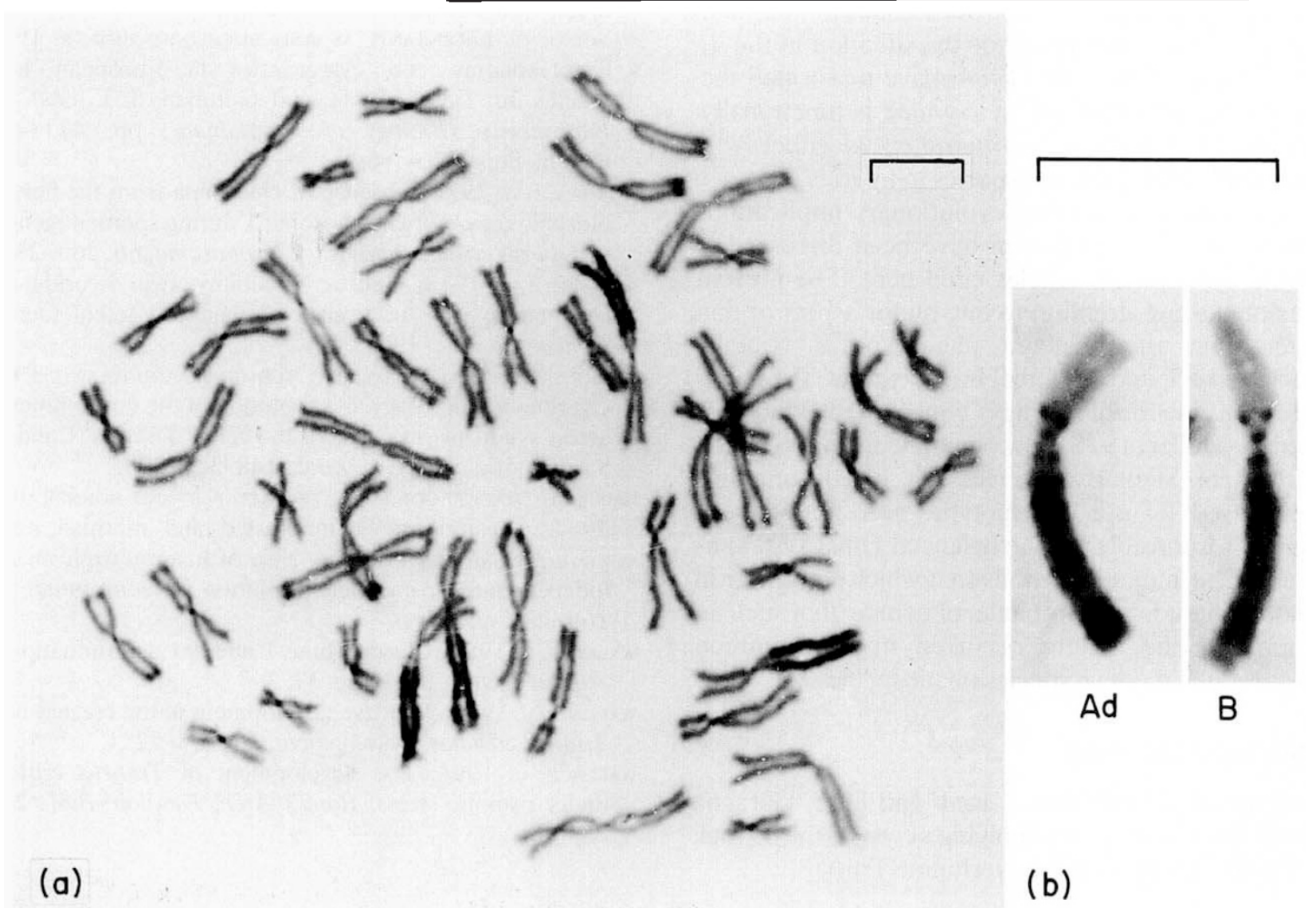

(b)

Fig. 2 (a) Two confluent metaphases from a normal Ap/B tailbud embryo. Chromosome 1 is identified by the heterochromatic long arms which all have pale tips, so $1 \mathrm{~A}$ and $1 \mathrm{~B}$ cannot be distinguished. (b) Chromosome 1 pair from an Ad/B metaphase. The dark tip of the long arm identifies 1 Ad. Bars represent $10 \mu \mathrm{m}$. 
The discrepancy between my identification of FT embryos as $1 \mathrm{~A} / 1 \mathrm{~A}$ homozygotes in carnifex (Table 3 ) and the identification of FT embryos as $1 \mathrm{~B} / 1 \mathrm{~B}$ in cristatus (Sessions et al., 1988) probably hinges on our definitions. Somatic $1 \mathrm{~A}$ and $1 \mathrm{~B}$ are recognized by the number and position of intensely stained bands within the heterochromatic segment. The bands coalesce as the chromosome contracts during prophase, decreasing from about ten to three or four. Furthermore, the pattern shows considerable variation in carnifex. The operational definition of $1 \mathrm{~A}$ used here and previously (Wallace, 1987) is that its heterochromatic segment contains more dark bands or thicker ones and generally appears darker that that of $1 \mathrm{~B}$. This is not an infallible definition but it corresponds to the illustrations of Macgregor \& Horner (1980), Macgregor et al. (1993) and Sims et al. (1984). Sessions et al. (1988) used an entirely different operational definition for cristatus, where $1 \mathrm{~A}$ was recognized by the absence of two distal dark bands which were present on $1 \mathrm{~B}$. Their criterion was evidently satisfactory for a single population of cristatus but might fail to apply for more general comparisons. The best resolution to this problem would be to determine which chromosome 1 variant is characteristic for each arrested class in T. marmoratus and use that as a reference point for the situation in the $T$. cristatus group. Sims et al. (1984) have performed the latter test to show that $1 \mathrm{~A}$ of carnifex is functionally equivalent to $1 \mathrm{~A}$ of $T$. marmoratus, as either will complement $1 \mathrm{~B}$ of the other species in hybrids.

The possible origins and evolutionary implications of this balanced lethal system have been discussed at length in most of the articles cited here. The present results only draw attention to one minor aspect of that debate. Since the blistered phenotype is virtually restricted to FT and ST lethal homozygotes, the mutation responsible for blistering is typical of the kind postulated by Muller (1918) to accumulate in any balanced lethal system. Similarly, the recessive lethal mutations which cause FT and ST phenotypes need not be those originally responsible for the balanced lethal system as they could be later acquisitions to it which act earlier in development. It is still probable, of course, that such an evolution of the system occurred in the common ancestor to the modern species or subspecies.

\section{Acknowledgements}

I am grateful to Professor C. Redi and Dr S. Garagna for their interest and for supplying newts of the $S$ stock and for the support of the Leverhulme Trust.

\section{References}

CALLAN, H. G. AND LLOYD, L. 1960. Lampbrush chromosomes of crested newts Triturus cristatus (Laurenti). Phil. Trans. R. Soc. Lond. B, 243, 135-219.

HORNER, H. A. AND MACGREgOR, H. C. 1985. Normal development in newts (Triturus) and its arrest as a consequence of an unusual chromosome situation. J. Herpetol., 19, 261-270.

MACGREGOR, H. C. AND HORNER, H. 1980. Heteromorphism for chromosome 1 , a requirement for normal development in crested newts. Chromosoma, 76, 111-122.

MACGREGOR, H. C., HORNER, H. A. AND SIMS, S. H. 1983. Newt chromosomes and some problems in evolutionary cytogenetics. In: Brandham, P. E. and Bennett, M. D. (eds), Kew Chromosome Conference II, pp. 283-294. Allen and Unwin, London.

MACGREgOR, H. C., SESSIONS, S. K. AND ARNTZEN, J. w. 1990. An integrative analysis of phylogenetic relationships among newts of the genus Triturus (family Salamandridae), using comparative biochemistry, cytogenetics and reproductive interactions. J. Evol. Biol., 3, 329-373.

MANCINO, G. 1991. Evolutionary cytogenetics of newts of the genus Triturus as revealed using monoclonal antibodies. In: Green, D. M. and Sessions, S. K. (eds) Amphibian Cytogenetics and Evolution, pp. 197-215. Academic Press, New York.

MANCINO, G., RAGGHIANTI, M. AND BUCCI-INNOCENTI, S. 1977. Cytotaxonomy and cytogenetics in European newt species. In: Taylor, D. H. and Guttman, S. I. (eds) The Reproductive Biology of Amphibians, pp. 411-447. Plenum Press, New York.

MORGAN, G. T. 1978. Absence of chiasmata from the heteromorphic region of chromosome 1 during spermatogenesis in Triturus cristatus carnifex. Chromosoma, 66, 269-280.

MULLER, H. J. 1918. Genetic variability, twin hybrids and constant hybrids in a case of balanced lethal factors. Genetics, 3, 422-499.

SESSIONS, S. K., MACGREGOR, H. C., SCHMID, M. AND HAAF, T. 1988. Cytology, embryology and evolution of the developmental arrest syndrome in newts of the genus Triturus (Caudata: Salamandridae). J. Exp. Zool., 248, 321-334.

SIMS, S. H., MACGREGOR, H. C., PELlatT, P. S. AND HORNER, H. A. 1984. Chromosome 1 in crested and marbled newts (Triturus): an extraordinary case of heteromorphism and independent chromosome evolution. Chromosoma, 89, $169-185$.

WAllace, H. 1984. Chromosome 1 and sex determination of crested newts. Caryologia, 37, 3-8.

WALlace, H. 1987. Abortive development in the crested newt Triturus cristatus. Development, 100, 65-72.

WALlACE, H. 1991. The development of Triturus cristatus under osmotic stress. Roux's Arch. Develop. Biol., 200, $58-60$. 